\title{
Contribuições do Maracatu de Baque Virado na Educação Antirracista
}

\author{
Michele Távora Julio \\ Pedagoga formada pela UNESP, campus Bauru e produtora cultural com diversos cursos na área. Possui \\ experiência em Educação com ênfase em Educação Infantil e Ensino Fundamental I, atualmente mestranda em \\ Educação no PPGE, da UFPB \\ $\triangle$ mtavorajulio@gmail.com
}

Recebido em 17 de agosto de 2020

Aceito em 9 de fevereiro de 2021

\section{Resumo:}

A criança quando brinca movimenta-se descobrindo além do seu corpo, o mundo e reinventa-se a cada desafio que lhe é proposto. Nesse processo relaciona-se com a cultura e o universo em que vive e desvenda a cada dia, dando significado a ele. Este artigo teve como objetivo geral descrever e refletir sobre a rotina e as características do desenvolvimento das crianças da Nação do Maracatu Porto Rico, localizada na Comunidade do Bode, em Recife-PE, a fim de compreender com mais apreço as particularidades da construção da identidade destas crianças e sua contribuição para uma Educação Antirracista. De natureza qualitativa e descritiva, foram analisados os documentos nacionais relativos à Educação Infantil e Relações Étnico-Raciais, evidenciando entrelaçamentos subjetivos com acontecimentos reais, das relações étnico-raciais na Educação. A pesquisa compreendeu o período do Carnaval 2016, acompanhando todo o processo carnavalesco que começou em setembro de 2015 até o momento final, com o desfile das agremiações campeãs. A Nação do Maracatu Porto Rico desempenha papel civilizacional na vida das crianças, com a incumbência de preservar a história de resistência da Comunidade do Bode, e atua na manutenção da luta contra o racismo e o preconceito religioso, e a valorização do (a) negro (a) que revela em sua estrutura a origem de matrizes africanas ou já elaboradas como afro-brasileira.

Palavras-chave: Maracatu de Baque Virado, Educação das Relações Étnico Raciais, Educação Antirracista.

\section{Contributions of Maracatu de Baque Virado in anti-racist Education}

\begin{abstract}
:
When playing, the child moves around discovering the world beyond his body, and reinvents himself with each challenge that is proposed. In this process, he relates to the culture and universe in which he lives and unravels each day, giving meaning to him. The general objective of this article was to describe and reflect on the routine and developmental characteristics of the children of the Maracatu Porto Rico Nation, located in the Bode Community, in Recife-PE, in order to better understand the particularities of identity construction of these children and their contribution to anti-racist education. Of a qualitative and descriptive nature, the national documents related to Early Childhood Education and Ethnic-Racial Relations were analyzed, showing subjective interlacing with real events, of ethnic-racial relations in Education. The research covered the period of Carnival 2016, following the entire carnival process which started in September 2015 until the final moment, with the parade of champion associations. The Nation of Maracatu Puerto Rico plays a civilizing role in the lives of children, with the task of preserving the history of resistance of the Bode Community, and acts in maintaining the fight against racism and religious prejudice, and the appreciation of black people that reveals in its structure the origin of African matrices or already elaborated as Afro-Brazilian. Keywords: Maracatu de Baque Virado, Education of Ethnic Racial Relations, Anti-racist Education.
\end{abstract}




\section{Contribuciones de Maracatu de Baque Virado en la educación antirracista}

\section{Resumen:}

Al jugar, el niño se mueve descubriendo el mundo más allá de su cuerpo y se reinventa a sí mismo con cada desafío que se le propone. En este proceso, se relaciona con la cultura y el universo en el que vive y se desenreda cada día, dándole sentido. El objetivo general de este artículo fue describir y reflexionar sobre las características rutinarias y de desarrollo de los niños de la Nación Maracatu Porto Rico, ubicada en la Comunidad Bode, en Recife-PE, con el fin de comprender mejor las particularidades de la construcción identitaria de estos. los niños y su contribución a la educación antirracista. De carácter cualitativo y descriptivo, se analizaron los documentos nacionales relacionados con la Educación Infantil y las Relaciones Étnico-Raciales, mostrando entrelazamientos subjetivos con hechos reales, de las relaciones étnico-raciales en Educación. La investigación abarcó el período del Carnaval 2016, siguiendo todo el Proceso de carnaval que se inició en septiembre de 2015 hasta el momento final, con el desfile de asociaciones campeonas. La Nación Maracatu Puerto Rico juega un papel civilizador en la vida de los niños, con la tarea de preservar la historia de resistencia de la Comunidad Bode, y actúa en el mantenimiento de la lucha contra el racismo y los prejuicios religiosos, y el aprecio de los negros que revela en su estructura el origen de matrices africanas o ya elaboradas como afrobrasileñas.

Palabras clave: Maracatu de Baque Virado, Educación en relaciones étnicas raciales, Educación antirracista.

\section{INTRODUÇÃO}

A curiosidade por este tema surgiu a partir do contato em 2013 com a Nação do Maracatu Porto Rico, em uma apresentação do grupo na cidade de São José do Rio Preto-SP. Com 102 anos de história e resistência, é sediada na Comunidade do Bode em Recife-PE, preservando a tradição dos seus ensinamentos além da sua ancestralidade até os dias atuais. Atuando na disseminação desta manifestação, com apresentações musicais não só no Brasil, mas também no mundo, a Nação do Maracatu Porto Rico tem uma particularidade: a constante presença das crianças da comunidade em todas as atividades desenvolvidas pelo grupo.

De inspiração etnográfica, em um primeiro momento, foi primordial para o desenvolvimento da pesquisa que se investigasse algumas hipóteses sobre a origem do Maracatu de Baque Virado ou Maracatu Nação, tendo como referência autores modernistas e contemporâneos, e o contexto histórico em que publicaram suas obras.

Na década de 1920, tendo o Manifesto Regionalista de 1926, com sede no Recife, como marco, houve um maior intercâmbio entre cultura erudita e cultura popular, na qual a manifestação artística, cultural e religiosa do Maracatu teve destaque, entendido não apenas como reminiscência de antigas práticas de negros africanos para a condição de cultura 
autenticamente pernambucana, de matriz africana, porém "abrasileirada" pela mestiçagem cultural que se promoveu e valorizou nesse período. Não é o foco deste artigo investigar sobre a história e a composição dos tipos de Maracatu, portanto algumas hipóteses sobre sua origem serão explanadas.

Investigar, descrever e refletir sobre os processos de construção da identidade das crianças que nascem e crescem em uma comunidade tendo um grupo de Maracatu de Baque Virado como seu brinquedo, onde recriam seus próprios símbolos, se movimentam, dançam e tocam instrumentos, pode ilustrar conceitos teóricos que abordam o desenvolvimento integral da criança como fruto da convivência social, promovidos pela interação desta com o meio social. Durante a pesquisa de campo, notou-se que as crianças estão presentes e participam de cada processo e acontecimento diário da Nação Porto Rico. Atuam desde a confecção dos instrumentos e das roupas, oficinas de música e dança, rituais religiosos, até nas apresentações musicais.

Em seu livro, Paulo Freire para educadores, Vera Barreto (1998) comenta uma reflexão de Paulo Freire, feita após uma viagem pelo continente africano, em que ele reconhece nossa linguagem corporal intrinsicamente ligada às nossas heranças africanas, pois o corpo tem sua própria linguagem, há uma integração entre gesto, palavra e atitude:

Um ensinamento fascinante está ligado ao uso do corpo, tal como se faz na África, bem como à importância da linguagem, tomada como expressividade total e não apenas estritamente linguístico. (BARRETO, 1998, p.35)

Com essas referências, orientações sobre o Maracatu de Baque Virado do ponto de vista dos jovens pertencentes à Comunidade do Bode foram buscadas, com a finalidade de ter uma maior compreensão sobre o processo de desenvolvimento e aprendizagem destas crianças.

Se por um lado o envolvimento emocional, a revolta perante os relatos de racismo, discriminação e preconceito sofrido constantemente pelos membros da Nação Porto Rico foram fatores encorajadores para a denúncia dessa realidade, por outro lado houve o receio durante o andamento da pesquisa, por se tratar de um tema delicado e tenso: nossas complexas relações étnico-raciais. 
Sabe-se que o conhecimento pode ser fragmentado e inacabado, pois está em um processo constante de aprimoramento e reparação, no qual objetividade pode ser incorporada pela subjetividade, e é necessário que haja um equilíbrio entre estas duas dimensões, o que nos é validado por Freire (1987, p. 20), "nem objetivismo, nem subjetivismo ou psicologismo, mas subjetividade e objetividade em permanente dialeticidade".

Assim sendo, a pesquisa constituiu-se em duas etapas concomitantes, de levantamento bibliográfico e de observações de campo a partir da presença na Comunidade do Bode, durante o processo do Carnaval de 2016. Com os elementos característicos da vida cotidiana, observada e registrada a partir de estudos e referenciais teóricos apresenta-se um breve relato da pesquisa neste artigo.

\section{Maracatu de Baque Virado ou Maracatu Nação}

Não é foco deste artigo o aprofundamento nas origens históricas desta manifestação. No entanto, é necessária uma breve apresentação sobre o Maracatu para sua contextualização e introdução.

Sua origem não foi totalmente esclarecida pelos diversos pesquisadores que se dedicaram a fazê-la, portanto trabalha-se sobre a hipótese mais aceita pelos escritores contemporâneos, segundo os quais existem, atualmente, a categorização de duas espécies de Maracatu em Pernambuco, diferentes em sua composição musical e corporal, são eles:

Maracatu de Baque Virado ou Maracatu Nação, que terá ênfase nessa pesquisa por ser a natureza da Nação do Maracatu Porto Rico, e o Maracatu Rural ou de Baque Solto. Sabe-se também da existência do Maracatu Cearense, com origem nos Maracatus de Pernambuco, mas que tem características próprias e bem diferentes dos pernambucanos:

Existe atualmente no Nordeste dois tipos de maracatus, o maracatu- nação ou baque-virado e o maracatu-rural, baque-solto ou maracatu de orquestra. Proponho ainda um terceiro que é o maracatu do Ceará, que mesmo se aproximando da estrutura do maracatu-nação, ainda exige uma outra tipologia, pois o ritmo é diferente, assim como alguns elementos constitutivos (SILVA, 2004, p. 30).

Há muitas pesquisas acerca de como e em que época teria surgido a manifestação cultural e religiosa do Maracatu de Baque Virado ou Maracatu Nação no Pernambuco. Pereira da Costa, folclorista e autor de diversas obras sobre a história e a cultura pernambucana, 
limita-se a apontar como tendo surgido nos “tempos do tráfico e escravidão” (COSTA, 1908, p. 35), em Pernambuco.

Uma das hipóteses mais aceitas pelos autores contemporâneos, é a de que o Maracatu de Baque Virado seja uma reinvenção das festas de coroação de reis negros, a instituição do Rei do Congo. Segundo Guerra Peixe (1952, p.13):

\begin{abstract}
A notícia mais remota até há pouco conhecida sobre a instituição dos Reis do Congo em Pernambuco, data de 1711, em Olinda [...] Todavia, os documentos encontrados há pouco na Igreja do Rosário em Recife revelam que a eleição e a coroação já haviam ocorrido neste lugar antes de 1711.Se as eleições de soberanos eram processadas em virtude da funcionalidade da instituição dos Reis do Congo, não parece arrojado presumir o seu estabelecimento desde pelo menos, 1674.
\end{abstract}

Com caráter político sempre atrelado à religiosidade, a instituição do Rei do Congo coroava reis e rainhas que governavam os negros, escravos ou não. Pereira da Costa relata que:

Cada cabeça de comarca, ou distrito paroquial, tinha o seu rei e rainha, com o competente cortejo de uma corte particular, e procedida a eleição, tinha lugar o ato solene da coroação e posse no dia da festa de Nossa Senhora do Rosário, impondo a coroa o pároco da freguesia. De toda essa diversidade de gente africana pela sua procedência de tribos distintas, somente a do Congo, escrava ou não, gozava do particular privilégio de eleger o seu rei, o seu Muquino-riá Congo, como lhe chamavam no idioma pátrio, cujo soberano superintendia sobre a gente das demais nações africanas, residentes no distrito de sua jurisdição. (COSTA,1908, p.214.)

Com a lei de abolição do tráfico, as coroações do Rei do Congo não perduraram, porém as músicas, o teatro e a dança permaneceram durante algum tempo e se transformaram no Auto dos Congos. Portanto, segundo Guerra Peixe (1952, p.12):

Desse modo, talvez encontremos as possíveis origens brasileiras do divertimento recifense, bem como a ocasião do seu aparecimento, se indagarmos: a) a época mais remota em que podemos supor o funcionamento da instituição do Rei do Congo; b) algumas relações que atariam os negros organizados em grupos quer administrativamente, quer quanto às festas profano-religiosas outrora praticadas; c) a maneira pela qual algumas reminiscências perdurariam até nossos dias.

Como herança da instituição do Rei dos Congos, de cunho político e religioso, ao Auto dos Congos, expressão teatral musical e de dança, temos o Maracatu Nação ou Baque Virado. 
Possivelmente, o desaparecimento da instituição do Rei do Congo e a decadência do Auto dos Congos levaram os reis a preencher seus cortejos com os membros das nações. E o aproveitamento das nações é que então teria induzido os populares recifenses a chamar o Maracatu de Baque Virado de "nação" - vocábulos que ainda hoje são empregados no mesmo sentido, ao mencionar o séquito (GUERRA PEIXE,1952, p. 13).

O conceito de Nação tem sua origem no período escravocrata, no qual "nações" de africanos eram escravos de diferentes etnias agrupados a partir do sistema organizacional do tráfico negreiro, levando-se em conta o Porto onde os africanos eram embarcados. Segundo Mariza Soares (2004, p. 303) a "nação" pode ser entendida como: "categoria que classifica e distribui os africanos no tráfico negreiro, migração forçada de africanos para o Brasil, em meados do século XVI até XIX, e seu significado se transforma: das "nações" de africanos escravizados para as "nações" de Candomblé".

Portanto, o conceito de Nação se modifica através do tempo, é utilizado nos Maracatus de Baque Virado, possuindo o mesmo significado do conceito de Nação para um terreiro de Candomblé, Ylê ou Xangô, que querem dizer a mesma coisa no Recife.

A conexão religiosa dos Maracatus revela-se através de suas sedes, que são os terreiros de Candomblé, Rainhas e Reis do Cortejo sendo representados pelas Iyalorixás (mãe de santo, posto mais elevado do Ylê, sendo a Rainha no Maracatu), pelos Babalorixás (pai de santo, posto mais elevado na hierarquia do Candomblé, que pode ser também o Mestre da Nação de Maracatu) e pelas calungas, bonecas negras de pano que representam os espíritos ancestrais e são carregadas no Cortejo pelas damas de paço:

Na verdade, a realeza desfila sob o pálio real, tendo à frente as calungas (bonecas consagradas aos Orixás), juntamente com outros elementos que formam o cortejo do maracatu, marca no espaço das ruas, sobretudo no período do carnaval, a extensão e o poder, no plano terreno, dos valores sagrados ali representados. (SILVA, 2004, p. 09)

Acontece atualmente no domingo de Carnaval, o Concurso das Agremiações Carnavalescas, realizada pela Secretaria de Cultura da Cidade do Recife, com os cortejos (desfiles) dos Maracatus Nação, constituído por personagens que anunciam a chegada do casal real, todos trajando fantasias, acompanhados por um conjunto percussivo com uma regência, cantando suas loas (toadas, músicas) e saudando seus ancestrais. 
Especificamente sobre a Nação Porto Rico, pertencente ao Ylê Axé Oxossi Guangoubira, cuja Rainha é a Iyalorixá Mãe Elda Viana. Para Jailson Viana Chacon, Mestre da Nação Porto Rico e Babalorixá do Ylê Axé Oxossi Guangoubira, o fundamento religioso é muito valorizado, tendo como particularidade desta Nação a introdução de atabaques:

\begin{abstract}
Mestre Chacon Viana defende o uso desse instrumento em seus batuques, tornandose o primeiro a inclui-lo no Maracatu, sob a justificativa de estar resgatando, segundo Guerra Peixe (1955) e Pereira da Costa (1908), uma antiga tradição. (DOSSIÊ DO MARACATU NAÇÃO: Inventário Nacional De Referências Culturais - INRC do Maracatu Nação, p. 65 e 66)
\end{abstract}

A ressignificação e o resgate destes elementos na cultura do Maracatu, transformando a história é explicado por Freire (1967, p.43):

A partir das relações do homem com a realidade, resultantes de estar com ela e de estar nela, pelos atos de criação, recriação e decisão, em que vai ele dinamizando o seu mundo. Vai dominando a realidade. Vai humanizando-a. Vai acrescentando a ela algo de que ele mesmo é o fazedor. (FREIRE, 1967, p.43)

É possível constatar a profunda conexão entre o Maracatu Nação e a espiritualidade dos orixás, como uma relação que se faz presente desde sua origem, resistindo aos processos históricos de opressão e violência até nossos dias atuais.

Porém, ao longo dos anos, atribuiu-se à esta manifestação um caráter de cultura popular, caracterizada como ato folclórico e não mais como um culto aos orixás. No entanto, o Maracatu não é apenas uma manifestação cultural, caracteriza-se também como uma reverência e celebração aos orixás, apesar de muitas Nações atualmente optarem por expressar essa consagração de forma imperceptível.

Segundo o Inventário Nacional de Referências Culturais do Maracatu Nação (DOSSIÊ,2017, p.11) hoje existem cerca de "26 comunidades de maracatu nação, situadas na Região Metropolitana de Recife, abrangendo as localidades de Recife, Olinda, Igarassu e Jaboatão dos Guararapes", localizadas em comunidades periféricas da cidade. Cada Nação tem sua linguagem, suas características e concepções próprias.

A seguir algumas considerações sobre as especificidades da Nação de Maracatu Porto Rico. 


\title{
Nação do Maracatu Porto Rico
}

A atual diretoria da Nação do Maracatu Porto Rico considera sua fundação em 07 de setembro de 1916, em Palmares/PE, sob liderança de João Francisco do Itá, porém Guerra Peixe (1955) abre a possibilidade, segundo sua pesquisa, de que poderia ter sido fundado dois anos antes e a data mencionada seria uma nova fase da agremiação:

\begin{abstract}
Examinamos velhos livros desse grupo. O mais antigo dizia: "Club Mixto Maracatu Porto Rico/ fundado em 7 de 9 de 1916. " Entre os nomes dos que compunham a diretoria constava os dos soberanos João Francisco da Silva e Maria dos Prazeres. Não há dúvidas, essa fundação não passa da nova fase da agremiação, porque Pereira da Costa transcreve em "Vocabulário Pernambucano", a seguinte nota publicada em jornal recifense, de 1914: "Fez ontem o seu dendê em frente a nossa tenda de trabalho o velho Maracatu Pôrto Rico". Nessa época já era um velho grupo o referido cortejo. (GUERRA PEIXE, 1955, p. 89)
\end{abstract}

Por falta de incentivo e pela forte repressão, a Nação Porto Rico entrou em crise, sendo anos mais tarde resgatada por Zé da Ferida, no bairro de Água Fria em Recife. Com a morte de Zé da Ferida, em 1950, a Nação Porto Rico é levada ao Museu do Carnaval.

Em 1967 José Eudes Chagas, babalorixá e fundador da Troça Carnavalesca Rei dos Ciganos, procura Katarina Real, antropóloga americana que estava residindo em Recife, para que esta lhe ajudasse na fundação de um Maracatu, o Porto Rico do Oriente:

Depois Eudes me explicou que a sede do Porto Rico do Oriente ficaria na sua casa particular no bairro do Pina, onde ele também atuava como babalorixá de um grande terreiro, trabalhando no Xangô e na Jurema. Informou-me que o povo do Pina queria continuar com a Troça Carnavalesca Rei dos Ciganos e que isto não causaria nenhum problema pois a Troça saía de dia e o Maracatu fazia sua apresentação de noite. (REAL, 2001, p. 28)

O período de 1967 a 1978, tempo que a Nação Porto Rico foi dirigida por Eudes, rendeu ao grupo homenagens da Comissão Pernambucana de Folclore e a vitória no carnaval de rua, na categoria Maracatu-Nação. Em 1978 com sua morte, as lideranças do grupo resolveram encerrar mais uma vez as atividades, mas o legado deixado por Eudes é grande:

O caso de Eudes Chagas é interessante por vários motivos. Ele atuou como rei, babalorixá e diretor do Porto Rico do Oriente de 1967 até 1978, um período de tempo relativamente curto para que seu "reino" recebesse a fama que mereceu posteriormente. Também, vale notar que Eudes nunca esteve interessado em publicidade ou promoção pessoal. Pelo que sabemos, ele nunca necessitou de um 
patrono de classe alta ou procurou o patrocínio de um político. Eudes confiava tanto em si mesmo, em sua inteligência e nos seus talentos de liderança, que raramente precisou pedir favores aos outros. Um homem sumamente feliz, ele compartilhava sua alegria contagiante com todos os que o conheciam. Acho que esta autoconfiança que ele demonstrava tão visivelmente, adivinha em grande parte da sua fé no xangô e nos orixás iorubanos, os quais lhe proporcionavam uma proteção especial e uma sabedoria fora do comum. (REAL, 2001, p.132)

A Nação do Maracatu Porto Rico ressurge em 1980, nas mãos de Mãe Elda Viana, “a maravilhosa Dona Elda Viana, a dinâmica rainha-iyalorixá do Porto Rico, herdeiro do maracatu de Eudes" (REAL, 2001, p.132), que foi coroada na Igreja de Nossa Senhora do Rosário dos Homens Pretos, e o Baque sendo dirigido por Mestre Jaime.

Mais tarde Mestre Chacon Viana assume o comando da bateria (baque) da Nação Porto Rico trazendo várias inovações, como a rica criação de novas loas (músicas) e com a introdução dos agbês e atabaques, em 2002. A composição do Cortejo é ainda preservada pela Nação Porto Rico, com os personagens da Corte Real, inclusive com a contemporaneidade da armação nos vestidos da Corte, o que garante mais beleza ao traje, novidade essa trazida por Mãe Elda, muito criticada na época, mas hoje, seguida pela maioria dos Maracatus que aderiram essa "moda" lançada por ela. A orquestra de percussão é formada pelos batuqueiros e seus instrumentos: alfaias, agbês, mineiros, atabaques, taróis, caixas e gonguê, além de uma voz solo, comandada pelo Mestre, e o coro de vozes. O Mestre comanda o Baque com seu apito, canta as loas, que é respondida pelo Coro, pelos batuqueiros e todos os integrantes que desfilam juntos, em blocos, em forma de "arrastão".

As loas da Nação Porto Rico contam a história do Maracatu, falam da tradição, do candomblé, dos tempos de escravidão e denunciam situações atuais, e atualmente Mestre Chacon compõe a maioria das loas do repertório.

\section{Brincar, jogar, cantar e dançar: a criança, a arte, a sacralidade e a ludicidade na Nação do Maracatu Porto Rico}

Recorrendo-se às Diretrizes Nacionais de Educação Infantil (BRASIL, 2010, p.12), verifica-se que a criança é: "Sujeito histórico e de direitos que, nas interações, relações e práticas cotidianas que vivencia, constrói sua identidade pessoal e coletiva, brinca, imagina, fantasia, deseja, aprende, observa, experimenta, narra, questiona e constrói sentidos sobre a natureza e a sociedade, produzindo cultura". 
Sabendo-se que a cultura é o resultado da criação humana, está relacionada às ideias, artefatos, costumes, leis, crenças morais, conhecimento, produzido a partir do convívio social, o ser humano cria tais ideias e leis.

Paulo Freire, nascido no Recife, um educador humanista e exímio conhecedor da cultura nordestina, traz a reflexão do pensamento político pedagógico atrelado ao conceito de cultura. Freire (1963) nos mostra que a cultura é toda produção humana acrescentada ao mundo pelo homem, resultado do seu trabalho humano, de sua criação e reinvenção:

A cultura como acrescentamento que o homem faz ao mundo que ele não fez. A cultura como resultado de seu trabalho. De seu esforço criador e recriador. 0 homem, afinal, no mundo e com o mundo, como sujeito e não como objeto. [...] descobrir-se-ia criticamente agora, como fazedor desse mundo da cultura. (FREIRE, 1963, p. 17).

Na Comunidade do Bode, de acordo com os dados coletados, a ideia de cultura é diversa entre os (as) moradores (as). A maioria acredita que apenas as pessoas que possuem Ensino Superior e/ou que pertencem a uma classe social alta são portadoras e produtoras de cultura. Nota-se nos relatos a concepção equivocada das pessoas entrevistadas na Comunidade do Bode acerca do conceito de cultura, gerando sentimentos de inferioridade. Provavelmente, resultantes de uma ideologia inerente a uma classe dominante que visa a domesticação.

Considerando criança e cultura, componentes chaves deste artigo buscou-se a concepção teórica no pensamento de Paulo Freire, que enxerga o educando como sujeito da história, tendo o diálogo e a troca como traço essencial no desenvolvimento da consciência crítica, princípio básico para a transformação.

Em “Ação cultural para Liberdade e outros escritos”, Freire (1981) enfatiza a importância do sujeito que se posiciona criticamente, reflete sobre sua limitação, atua e reconhece seu espaço no mundo, podendo assim alcançar a liberdade e transformar a realidade condicionante:

Enquanto o ser que simplesmente vive não é capaz de refletir sobre si mesmo e saber-se vivendo no mundo, o sujeito existente reflete sobre sua vida, no domínio mesmo da existência e se pergunta em torno de suas relações com o mundo. 0 
domínio da existência é o domínio do trabalho, da cultura, da história, dos valores domínio em que os seres humanos experimentam a dialética entre determinação e liberdade. (FREIRE, 1981, p.53).

Nesta perspectiva, a relação das crianças atuantes no Maracatu, que por sua vez possui dimensão e ligação com o Candomblé, também nos remete à reflexão da conexão entre cultura e religiosidade. Para Geertz (1989), a religiosidade é um agrupamento de simbologias que se efetivam através dos rituais e das vivências:

Denota um padrão de significados transmitidos historicamente, incorporados em símbolos, um sistema de concepções herdadas expressas em formas simbólicas por meios das quais os homens comunicam, perpetuam e desenvolvem seu conhecimento e suas atividades em relação à vida. (GEERTZ,1989, p. 103)

Sobre religiosidade, Freire (1967) expõe que o existir no mundo ultrapassa o viver. Transcender, discernir, dialogar são exclusividades do existir. O existir é individual, mas só se realiza em relação com outros existires, em comunicação com eles:

A sua transcendência está também, para nós, na raiz de sua finitude. Na consciência que tem desta finitude. Do ser inacabado que é e cuja plenitude se acha na ligação com seu Criador. Ligação que, pela própria essência, jamais será de dominação ou de domesticação, mas sempre de libertação. Daí que a Religião - religare - que encarna este sentido transcendental das relações do homem, jamais deva ser um instrumento de sua alienação. Exatamente porque, ser finito e indigente, tem o homem na transcendência, pelo amor, o seu retorno à sua Fonte, que o liberta. No ato de discernir, porque existe e não só vive, se acha a raiz. (FREIRE, 1967, p.40).

Vista dessa forma, a religiosidade do Candomblé não diz respeito somente ao sobrenatural e à parte ritualística, mas à sociedade em que está inserida. Ela se torna uma expressão simbólica, na qual as pessoas compartilham valores e significados, o que gera uma junção entre todos, produzindo solidariedade e a construção de uma extensa família.

O Maracatu de Baque Virado, deste modo, representa o brinquedo do Candomblé, porém é importante relatar que, apesar de ser considerado brinquedo, são feitas as obrigações religiosas (ritual em que se oferece oferendas aos orixás) antes do Carnaval nas calungas, as bonecas de pano, e alguns tambores ou como são chamados no Maracatu, alfaias, para que o Maracatu saia no desfile oficial com proteção e benção dos orixás. 
Para melhor explicitar a relação do Maracatu como brinquedo, temos uma passagem do livro Eudes, o Rei do maracatu, da antropóloga americana Katarina Real, que registrou a recriação da Nação Porto Rico pelo Babalorixá José Eudes Chagas, de quem se tornou muito amiga. Em entrevista à Katarina, no ano de 1967, Eudes Chagas explica o porquê do surgimento da Troça Carnavalesca Rei dos Ciganos, que mais tarde viria a ser o MaracatuNação Porto Rico do Oriente (a Nação Porto Rico hoje), e sua relação como filho de santo da Iyalorixá dona Santa, rainha do legendário Maracatu Elefante:

\begin{abstract}
Eu estava no segundo quarto com dona Santa. Ela fez a recomendação e fez o amassi [a lavagem da cabeça do filho de santo com ervas especiais do ritual iorubano]. 'É o batismo', ela disse, e me contou que eu teria que seguir a seita porque os orixás Ogum e Xangô estavam me acompanhando. Cheguei a gozar de saúde durante um ano e seis meses sem compromisso. Mas voltou o incômodo. Estava com 16 anos. Fiquei apavorado e voltei à Casa de dona Santa. Ela me repreendeu severamente. Depois disse-me, 'Quero que você organize um brinquedo em sua casa, um maracatu disfarçado, para evitar problemas com a polícia'. Chamei os colegas da seita e fundamos a Troça Rei dos Ciganos, em 5 de outubro de 1938. (REAL, 2001, p.22).
\end{abstract}

Eudes também relata como era feito o culto camuflado aos orixás para evitar represálias da polícia, mencionando inclusive a improvisação do Peji, o nome dado ao altar sagrado dos orixás:

\begin{abstract}
Mesmo com a polícia vigiando a gente, tivemos que fazer as obrigações para os santos. Assim, combinamos um meio de improvisar nosso peji. Lá na sede da Troça em Beberibe (que era nosso terreiro), fizemos um coreto de madeira com uma entrada embaixo para colocar as coisas dos santos. No dia em que íamos fazer uma obrigação, anunciávamos um baile e convidávamos os participantes (os colegas da seita) e o público- e, às vezes, até a própria polícia. O povo dançava em cima do tablado, debaixo do qual o peji estava escondido. Anunciávamos um Baile Azul em dezembro para homenagear Iemanjá e um Baile Branco na noite de ano para Orixalá. Fizemos também um Baile Rosa para Iansã no dia 4 de dezembro. (REAL, 2001, p.23).
\end{abstract}

Atualmente, as calungas (bonecas) da Nação Porto Rico que recebem obrigação são: dona Inês (Oyá), dona Elizabete (Oxum), dona Júlia (Oxalá) e dona Bela (Pomba Gira). Cada uma delas é levada por uma dama do paço durante as apresentações, função de grande responsabilidade assumida por mulheres que passam por preparativos dentro do Ylê para que possam carregar as calungas. Não é preciso ser do Candomblé para ser uma dama do paço, todavia é importante que respeite e cumpra os preceitos religiosos. 
Durante a obrigação religiosa do Carnaval de 2016, foi verificado que as crianças observam tudo e algumas ajudam a separar as folhas para o banho de amassi (composto de diversas ervas que tem a função de limpar e proteger o corpo da pessoa), até mesmo algumas crianças batuqueiras que não são do Candomblé participam do ritual com muita naturalidade.

Compreender o Maracatu como brinquedo pode ser complexo, pois o mais comum é pensarmos na palavra brinquedo e a associarmos à um objeto. Porém nesta visão, o brinquedo transcende o objeto, ganha vida, força, axé (energia). Quando indagadas sobre a relação do Maracatu com a palavra brinquedo, algumas crianças formaram uma "rodinha" e responderam de forma unânime: "Maracatu é brinquedo".

Instigando-as, aparecem algumas definições mais elaboradas como: "Maracatu é brincadeira séria", "é festa", "é tudo isso aqui, é música, é dança, é Candomblé, é alegria”, "é para todo mundo brincar".

\title{
Mas que brincar é esse?
}

As crianças batuqueiras da Nação Porto Rico são naturalmente curiosas, aprendem e ensinam outras crianças aquilo que lhes traz prazer e as envolve em ações lúdicas, pois sua forma de agir e de pensar é pelo brincar. Estão em toda parte, seja no Ylê Axé Oxossi Guangoubira, seja em atividades no Maracatu Porto Rico ou no Ponto de Cultura Nação Porto Rico:

\begin{abstract}
Ponto de Cultura "Nação Porto Rico" é um projeto piloto que tem como compromisso transformar a sede da Nação do Maracatu Porto Rico em um Centro Cultural de Tradições Afro-Ameríndias Pernambucanas, na cidade de Recife-PE. O objetivo é promover a inclusão sociocultural de crianças, adolescentes, jovens e adultos afrodescendentes, por meio da valorização da memória sobre elementos da cultura popular pernambucana e o ensino de práticas manuais e técnicas construtivas para a continuidade destas expressões étnicas entre as futuras gerações. São oferecidas oficinas de: Confecção de adereços e adornos para Maracatu; Confecção de instrumentos de percussão para Maracatu; Corte e Costura para confecção de roupas para Maracatu; Inclusão digital (informática básica e para áudio/vídeo); Ludicidade; Capoeira; Palestras com Mestre da cultura Nagô e tradição da Nação. (NAÇÃO PORTO RICO, 2017, on line).
\end{abstract}

Como se dá a valorização da memória, dos elementos da cultura popular pernambucana, as oficinas de Música e Dança e o ensino de práticas manuais e técnicas para estas crianças no Ponto de Cultura? Tal questionamento teve como fundo conhecer as ações realizadas pelos (as) educadores (as) do Ponto de Cultura Nação de Maracatu Porto Rico. 
$\mathrm{O}$ apoio dos Pontos de Cultura espalhados no Brasil vem permitindo que em diversos lugares a cultura se mantenha, persista e assim o papel desses espaços e seu estudo são fundamentais:

É a entidade cultural ou coletivo cultural certificado pelo Ministério da Cultura. Trata-se de uma política cultural que, ao ganhar escala e articulação com programas sociais do governo e de outros ministérios, pode partir da Cultura para fazer a disputa simbólica e econômica na base da sociedade. (BRASIL, 2016, p.90).

As oficinas oferecidas são diversas: confecção de instrumentos de percussão; adereços e fantasias; informática básica; dança; canto; percussão; curumins do Ylê; história da Nação de Maracatu Porto Rico-Projeto de Extensão em parceria com o Instituto Federal de Pernambuco- IFPE. Todas as oficinas são abertas às crianças e foi verificado no período da visita à campo que o número de crianças participantes nunca é menor que quinze e há dois projetos: Baque Mirim e Curumins do Ylê, com o objetivo de dar um direcionamento para as crianças da Comunidade do Bode. A proposta pedagógica vai desde contação e recontação de histórias da mitologia afro indígena brasileira até noções de higiene pessoal, em que as crianças se expressam através das atividades e intervenções lúdicas, treinam a democracia interna ao escutarem e pensarem na proposta de outros coleguinhas. Os adultos são parte do apoio, tem atividades internas no Ylê e no Ponto de cultura, bem como na área externa com limpeza da rua a partir de noções de defesa do meio ambiente e natureza, morada dos Orixás, e na praia do Pina.

Vemos, portanto, que o trabalho educacional do Ponto de Cultura da Nação Porto Rico oportuniza aprendizagens significativas para as crianças. Não ocorre somente de forma ocasional, há uma intencionalidade, com conhecimentos sistematizados e questões referentes à prática social para o exercício da cidadania, na perspectiva da participação política, buscando soluções para os problemas cotidianos da Comunidade. Aprende-se e ensina-se com novas visões, trazendo novas perspectivas de pensar e de agir perante o mundo, de modo solidário, coletivo e popular.

Assim, envolvida em todas essas atividades, embaladas pelas batidas das alfaias (tambores) do Maracatu e os ilús (atabaques usados em candomblés de Nação Nagô), a música e a dança, para essas crianças, são partes integradas da sua forma de viver e de se comunicar com adultos, outras crianças e consigo mesma. Sobre isso, Freire nos aponta que, “[...] a 
comunicação, é diálogo, na medida em que não é transferência de saber, mas um encontro de sujeitos interlocutores que buscam a significação dos significados" (FREIRE, 1982, p. 69).

Além de participarem nos diversos âmbitos de construção para que a Nação do Maracatu Porto Rico possa desfilar nas ruas de Recife durante todo o ano em eventos e no Carnaval, tendo inclusive autonomia para organizar seus próprios ensaios e apresentações, as crianças possuem seu próprio grupo: o Maracatu Porto Rico Mirim.

Um fato observado nos ensaios e na convivência diária com esses meninos e meninas, é relativo aos valores atrelados ao Candomblé, como respeito aos mais velhos, o compromisso com a disseminação fidedigna dos saberes, entre outros, sendo atribuídos e incorporados nas atitudes de crianças que participam do Baque Mirim, mesmo nas que não são adeptas do Candomblé. Geertz (1989) considera que estes valores morais e estéticos de uma dada cultura e a atitude que o indivíduo exerce em relação a si mesmo e ao mundo que a cerca revela que:

A crença religiosa e o ritual confrontam e confirmam-se mutuamente. [...] E a visão de mundo torna-se emocionalmente aceitável por se apresentar como imagem de um verdadeiro estado de coisas do qual esse tipo de vida é expressão autêntica. Essa demonstração de uma relação significativa entre os valores que o povo conserva e a ordem geral da existência dentro da qual ele se encontra é um elemento essencial em todas as religiões, como quer que esses valores ou essa ordem sejam concebidas. (GEERTZ, 1989, p.95).

Estes valores, influenciando também nos gestos e nos pensamentos das crianças, é o que possibilita a relação dela com o transcendental, "[...] toda religião se compõe da tradição de gestos estereotipados e de imagens mentais, ritos e mitos respectivamente" (BASTIDE, 1971, p. 333). Muitas brincadeiras advêm da vivência em terreiro, com as especificações que cabe ao culto de cada orixá, tão bem conhecidas por elas. Frequentemente estão cantando, fazendo algum toque nos atabaques ou dançando para os orixás.

Vincular a criança à realidade onde vive, como produtora de sua cultura, na qual constrói sua identidade individual e coletiva, é primordial pois acredita-se que o princípio da identidade da criança está no meio social em que vive e atua. 0 processo de desenvolvimento da identidade e, consequentemente de autonomia, está relacionado com as interações sociais. Quando a criança consegue compreender essa dimensão do sagrado, da música, da dança e 
sua composição brincando, desenvolve sua identidade com a cultura onde está inserida, é nesta interação que ela constrói os saberes que vão acompanha-la por toda vida.

Essa vivência oportuniza a apropriação dos valores, crenças e conhecimentos do grupo ao qual pertence, como nos aponta o documento do Referencial Curricular para a Educação Infantil- RCNEI:

A identidade é um conceito do qual faz parte a ideia de distinção, de uma marca de diferença entre as pessoas, a começar pelo nome, seguido de todas as características físicas, de modos de agir e de pensar e da história pessoal. Sua construção é gradativa e se dá por meio de interações sociais estabelecidas pela criança, nas quais ela, alternadamente, imita e se funde com o outro para diferenciar-se dele em seguida, muitas vezes utilizando-se da oposição. A fonte original da identidade está naquele círculo de pessoas com quem a criança interage no início da vida. (BRASIL,1998, p.12).

A união de vários povos, reminiscências europeias e de várias etnias africanas e indígenas, faz do Brasil um país muito diversificado culturalmente. Essas relações étnicoraciais se tornam complexas sendo necessário que a compreendamos como resultado das construções culturais, políticas e sociais, produzidas a partir de um profundo processo histórico. De acordo com Gomes (2010, p.24):

\begin{abstract}
Demonstra que, para se compreender a realidade do negro brasileiro, não somente as características físicas e classificação racial devem ser consideradas, mas também a dimensão simbólica, cultural territorial, mítica, política e identitária. Nesse aspecto, é bom lembrar que nem sempre a forma como a sociedade classifica racialmente uma pessoa corresponde, necessariamente, à forma como ela se vê. 0 que isso significa? Significa que, para compreendermos as relações étnico-raciais de maneira aprofundada, temos de considerar os processos identitários vividos pelos sujeitos, os quais interferem no modo como esses se veem, identificam-se e falam de si mesmos e do seu pertencimento étnico-racial.
\end{abstract}

Assim sendo, reflete-se sobre a urgência em ouvir e compreender o processo identitário oriundo das relações étnico-raciais e culturais pela ótica da própria criança e adolescente, visto ser evidente que a discriminação, o preconceito, a ignorância, o racismo e a peculiaridade dificultam muito as pesquisas sobre o tema:

É importante tomar conhecimento da complexidade que envolve o processo de construção da identidade negra [...] Processo esse, marcado por uma sociedade que, para discriminar os negros, utiliza-se tanto da desvalorização da cultura de matriz 
africana como dos aspectos físicos herdados pelos descendentes de africanos. Nesse processo complexo, é possível, no Brasil, que algumas pessoas de tez clara e traços físicos europeus, em virtude de o pai ou a mãe ser negro (a), se designarem negros; que outros, com traços físicos africanos, se digam brancos. É preciso lembrar que o termo negro começou a ser usado pelos senhores para designar pejorativamente os escravizados e este sentido negativo da palavra se estende até hoje. Contudo, o Movimento Negro ressignificou esse termo dando-lhe um sentido político e positivo (BRASIL, 2005, p.15).

Cabe salientar que embora o termo "raça", do ponto de vista biológico, já tenha ficado ultrapassado para nomeação dos indivíduos, por se compreender que não existem diferenças consideráveis que fundamentem a classificação dos seres humanos em "raças", do ponto de vista social e do senso comum, o termo está bastante presente, trazendo até mesmo o mito da existência da democracia racial no nosso país:

Qualquer estudo sobre o racismo no Brasil deve começar por notar que o racismo no Brasil é um tabu. De fato, os brasileiros se imaginam numa democracia racial. Essa é uma fonte de orgulho nacional, e serve, no nosso confronto/comparação com outras nações, como prova inconteste de nosso status de povo civilizado. (GUIMARÃES, 1999, p.26)

Gomes (2005) ressalta que a expressão "raça” é utilizada para fazer alusão à população negra, pois a "raça" tem funcionalidade na cultura e na vida social, faz com que as pessoas sejam identificadas e, por vezes, classificadas, subalternizadas e excluídas por suas características, ou seja, traços fenotípicos:

O conceito de raça é adotado, nessa perspectiva, com um significado político e identitário construído com base na análise do tipo de racismo que existe no contexto brasileiro, as suas formas de superação e considerando as dimensões histórica e cultural a que esse processo complexo nos remete (GOMES, 2005, p. 22).

Mesmo com as dificuldades e considerando o processo histórico de integração e valorização da cultura negra africana e afrodescendente no Brasil, ao longo dos anos, é importante nos propormos a compreender e discutir as relações étnico-raciais, em toda sua amplitude:

[...] A busca da identidade, no nosso caso no Brasil, apesar da importância, não é uma coisa fácil; é problemática. Essa identidade passa pela cor da pele, pela cultura, ou pela produção cultural do negro, passa pela contribuição histórica do negro na sociedade brasileira, na construção da economia do país com seu sangue; passa pela 
recuperação de sua história africana, de sua visão do mundo, de sua religião. (MUNANGA, 1996, p. 225).

A instituição escolar também faz parte do cotidiano dessas crianças, um espaço de troca de experiências, conhecimento sistematizado e influências de valores que afetam diretamente o aprendizado desses (as) discentes e o trabalho dos (as) docentes. São inúmeras dificuldades em diversos âmbitos no ambiente escolar para que o processo ensino aprendizagem aconteça em sua plenitude. O processo de construção da identidade das crianças acontece simultaneamente à experiência da sua vida escolar e:

Nesse caso, a escola tem a responsabilidade social e educativa de compreendê-la na sua complexidade, respeitá-la, assim como às outras identidades construídas pelos sujeitos que atuam no processo educativo escolar, e lidar positivamente com a mesma. (GOMES, 2005, p. 44).

Durante a visita à Comunidade do Bode não foi possível acompanhar a rotina escolar das crianças, pois encontravam-se em período de férias. Algumas crianças compartilharam que não há nenhuma relação do Maracatu com a vida escolar cotidiana. Percebe-se que sobre esse assunto, as crianças apresentam-se relutantes e esquivam-se das perguntas.

É comum ouvir relatos das crianças e adolescentes de que nas escolas, as manifestações culturais como o Maracatu de Baque Virado, são tratadas pejorativamente como folclore (aqui o conceito de folclore seria o de mito ou lenda) ou lembradas só em momentos como o mês da Consciência Negra, que ocorre em novembro.

Essa situação é muito preocupante visto que "só é possível o indivíduo manter sua auto identificação como pessoa de importância no meio que confirma essa identidade. " (BERGER, LUCKMANN, 2004, p. 230). Em um ambiente hostil, em que sofre preconceito e/ou tem sua cultura silenciada, como a criança pode se defender e afirmar sua identidade, ainda em construção? O quanto o meio e a interação social são extremamente importantes para seu desenvolvimento? Como essa criança pode se identificar com aquilo que lhe chega de forma depreciativa?

Outro fato preocupante são os conteúdos escolhidos para compor os currículos, que chegam, na maioria das vezes, prontos na escola, produzidos por uma organização 
estruturada, envolvendo também formas de avaliação e até mesmo normas e valores de como viver a vida dentro da escola. Quando temos um sistema educacional distribuído de uma forma vertical, no qual um grupo minoritário de pessoas estabelece o currículo oficial sem conhecer a realidade da escola e dos discentes, Santomé (1995, p. 169) denuncia que os atos criminosos do racismo vão fincando suas raízes desde cedo em crianças e adolescentes:

São numerosas as formas através das quais o racismo aflora no sistema educacional, de forma consciente ou oculta. Assim, por exemplo, podem-se detectar manifestações de racismo nos livros didáticos de Ciências Sociais, História, Geografia, Literatura, etc., especialmente através dos silêncios que são produzidos em relação aos direitos e características das comunidades, etnias e povos minoritários e sem poder. [...] as atitudes de racismo e discriminação costumam ser dissimuladas também recorrendo a descrições dominadas por estereótipos e pelo silenciamento de acontecimentos históricos, socioeconômicos e culturais.

Em Professora sim, tia não, Freire (1997) ressalta a importância e a responsabilidade que se é trabalhar na Educação, na qual a dimensão da ignorância do (a) docente causa danos irreversíveis em vidas, pois estamos tratando de seres humanos, únicos em suas especificidades:

A prática educativa, pelo contrário, é algo muito sério. Lidamos com gente, com crianças, adolescentes ou adultos. Participamos de sua formação. Ajudamo-los ou os prejudicamos nesta busca. Estamos intrinsecamente a eles ligados no seu processo de conhecimento. Podemos concorrer com nossa incompetência, má preparação, irresponsabilidade, para o seu fracasso. Mas podemos, também, com nossa responsabilidade, preparo científico e gosto do ensino, com nossa seriedade e testemunho de luta contra as injustiças, contribuir para que os educandos vão se tornando presenças marcantes no mundo. (FREIRE, 1997, p.32).

Apesar da Lei 10.639/03, que visa desvelar a história africana e afro-brasileira propondo atuação pedagógica no combate ao racismo, discriminação e preconceito, não a vemos ser constantemente aplicada nas escolas, o que seria o correto e consta nos documentos nacionais:

Baseados nisso é que evidenciamos a questão da cultura étnica na escola. Estudos e pesquisas de Silva (1993) e Gomes (1996) vêm demonstrando que a cultura de origem africana na escola tem sido, de certa forma silenciada, quando não excluída dos processos de formação de nossos professores (as), consequentemente impossibilitando que as crianças negras possam reafirmar suas identidades culturais. (CLEMENCIO, 2004, p.98). 
Por consequência, Sousa (2005, p. 114) denuncia que "os instrumentos legitimadores como escola e mídias tendem a desqualificar os atributos dos segmentos étnico-racial negro". Algumas famílias relataram que muitas crianças deixam de ir à escola ou acabam faltando demasiadamente às aulas, por sofrerem racismo, discriminação e preconceito na escola, pois em alguns casos os membros da equipe escolar se omitem, fingem não ver o que acontece, em outros casos realmente desconhecem os ocorridos e o pior, também cometem atos discriminatórios para com as crianças do Maracatu Porto Rico ou do Ylê Axé Oxossi Gangoubira.

Essa escola idealizada, atenta aos movimentos culturais advindos da sociedade, como projeto político pedagógico consistente está muito longe de ser realidade. Seria uma utopia ter uma escola que deva "vincular-se à luta pelos direitos, com o movimento civilizatório, humanizador, cultural, e não apenas com as demandas do mercado? "(ARROYO, 1996, p.169):

Há que se fazer uma leitura crítica e contextualizada de como estão sendo formados nossos (as) professores (as), que conhecimentos estão adquirindo, em que condições estão sendo preparados (as) e quais os instrumentos de construção / manutenção / transformação sociocultural de que vão dispor na escola. É uma tarefa eficaz no trato com a diversidade, se pensarmos que os (as) professores (as) estão na condição de produção / reprodução dos discursos e práticas na escola e que nestas estão implicadas sua cultura, sua etnia e suas múltiplas identidades. (CLEMENCIO,2004, p. 107).

Não foi possível entrevistar docentes e coordenação pedagógica na época da pesquisa, pelo fato de que se encontravam em período de férias. Pelo que foi verificado através dos relatos das crianças e das famílias, as escolas em que as crianças batuqueiras estão matriculadas, particulares ou públicas, apresentam-se como conservadoras e de caráter assimilacionista, um "multiculturalismo conservador segue Hume (GOLDBERG, 1994) ao insistir na assimilação da diferença às tradições e costumes da maioria." (HALL, 2003, p.53).

Para combater essa problemática há um grande esforço das famílias da Comunidade do Bode e as organizações nela presentes como, o Ponto de Cultura Nação Porto Rico, no intuito de educar, denunciar, reivindicar e combater o costume criminoso de inferiorização e subjugação dos africanos e afro descendentes, visto que:

A escola é o espaço onde as classes e grupos desprestigiados pela sociedade iniciam um momento de ruptura com o seu modo de viver, de aprender, de significar. É 
também o espaço em que estas classes e grupos creditam a possibilidade de ascensão cultural, social e econômica. Também é na escola que vemos, em maior ou menor grau, a assimilação de um modelo cultural tido como superior. (CLEMENCIO, 2004, p.95).

Diante de todos esses aspectos aqui observados e analisados, encontra-se a seguir algumas reflexões finais.

\section{CONSIDERAÇÕES FINAIS}

Em relação à vida escolar das crianças batuqueiras e frente à nossa complexidade étnico-cultural, suas diversas fontes que alimentam nossa identidade, do papel fundamental que a escola desempenha neste processo, o repertório cultural destas crianças da Comunidade do Bode pode transformar, criar e recriar o mundo à sua volta, visto que em seus processos de aprendizagem fora do ambiente escolar, possuem flexibilidade e respeito às dificuldades e capacidades de cada uma.

Nesse contexto, sendo a educação escolar parte do processo de construção da identidade das crianças, a escola está sendo desafiada a elaborar estratégias de interação para agregar uma coletividade que partilha valores, saberes, tradições e uma história em comum, respeitando as questões étnico-raciais e culturais, que estão em um movimento constante de afirmação e atualização. Assim, o sistema educacional, ganha caráter de urgência para fazer frente às estas ideias, visto que, na prática, desistoriciza a história dos africanos e dos afrobrasileiros, caminhando na contramão das normas instituídas pela Constituição Federal.

As instituições educacionais formais atuam dessa forma como reprodutora das relações de poder presentes na sociedade, tendo em vista a seleção dos conteúdos dos currículos, com livros didáticos que confirmam a hegemonia das culturas dominantes e tornam exóticas as culturas dominadas. Também há a atuação dos (as) professores (as) e da equipe escolar, que agem a partir de seus pontos de vistas, praticando currículo oculto, o que implica em racismo, preconceito e discriminação com as crianças, evidenciando o processo da dominação baseada nas complexas relações étnico-raciais. Silva (2004, p. 102) traz a reflexão: "como desconstruir o texto racial do currículo, como questionar as narrativas 
hegemônicas de identidades que constituem o currículo? ". Ela propõe o questionamento dos mecanismos de construção das identidades étnico-raciais e suas ligações com as relações de poder.

Há que se incorporar na dinâmica escolar ações de cidadania que objetivem preservar, reconhecer e valorizar as raízes africanas e a eficácia do cumprimento da lei 10.639/03. Segundo os relatos das crianças, por si mesmas já se deram conta de que só são valorizadas e reconhecidas na Semana da Consciência Negra, no mês de novembro. Pensando na escola como um espaço de organização, produção e reprodução de conhecimento, interação social, o respeito e a dignidade a todos os seres devem vir o ano todo e a todo momento. A favor do combate ao preconceito, à discriminação e ao racismo; a abordagem étnica-racial; o respeito à todas as culturas e o amplo debate sobre as demandas cotidianas que se apresentam em uma escola. Nas palavras de Hall (2003) a realidade do sistema educacional brasileiro:

\begin{abstract}
Já as estratégias culturais capazes de fazer diferença são o que me interessa - aquelas capazes de efetuar diferenças e de deslocar as disposições do poder. Reconheço que os espaços "conquistados" para as diferenças ainda são poucos e dispersos, e cuidadosamente policiados e regulados. Sei que eles são absurdamente subfinanciados, que existe sempre um preço de cooptação a ser pago quando o lado cortante da diferença perde o fio na espetacularização, que o que substitui a invisibilidade é uma espécie de visibilidade cuidadosamente regulada e segregada. (HALL, 2003, p. 339)
\end{abstract}

É preciso desconstruir a lógica, principalmente nas pesquisas sobre as relações étnicoraciais na Educação, de olhar para os (as) negros (as) como identidades marginais, marcando a diferença que culminam em desvios da norma, derivados das diferentes inserções sociais e culturais das crianças.

Finalmente, podemos dizer que, é atribuído ao Maracatu, especificamente à Nação do Maracatu do Porto Rico, um papel civilizacional no resgate para combater e denunciar o genocídio das pessoas negras, através de práticas pedagógicas e culturais com as crianças e adolescentes da Comunidade do Bode. Atribui-se também a incumbência de preservar a história de resistência deste povo, tradição de uma comunidade, na manutenção da luta contra o racismo, a discriminação e o preconceito, e a valorização do (a) negro (a) que revela em sua estrutura a origem provinda de matrizes africanas ou já elaboradas como afrobrasileiras. 


\section{REFERÊNCIAS BIBLIOGRÁFICAS}

ARROYO, Miguel G. Assumir nossa diversidade cultural. Revista de Educação AE, v. 25, n.98, jan.mar.1996.

BARRETO, Vera. Paulo Freire para educadores. São Paulo: Arte\& Ciência, 1998.

BASTIDE, Roger. As religiões africanas no Brasil. São Paulo: Livraria Pioneira Editora, 1971, v.2.

BERGER, Peter L. LUCKMANN, Thomas. A construção social da realidade: tratado de sociologia do conhecimento. Rio de Janeiro: Editora Vozes, 2004.

BRASIL, Ministério da Educação e do Desporto. Secretaria de Educação Fundamental. Referencial Curricular Nacional para Educação Infantil. Brasília: MEC/SEF, v. 3,1998. BRASIL. Ministério da Educação. Secretaria Especial de Políticas de Promoção de Igualdade Racial - SEPPIR. Diretrizes Curriculares Nacionais para a Educação das Relações Étnico-Raciais e para o Ensino de História e Cultura Afro-brasileira e Africana. Brasília: Inep, 2005.

BRASIL. Ministério da Educação. Secretaria de Educação Básica. Diretrizes curriculares nacionais para a educação infantil /Secretaria de Educação Básica. Brasília: MEC, SEB, 2010.

BRASIL. Ponto de cultura. Disponível em: <http://cultura.gov.br/?s=o+que+\%C3\%A9+ponto+de+cultura >.Acesso em: 1 maio 2016.

CLEMÊNCIO, Aparecida Maria. Os professores e a escola: lidando com a diversidade étnica. Brinquedos e Companhia: São Paulo: Cortez, 2004.

COSTA, Francisco Augusto Pereira da. Folk-lore pernambucano. Revista do IHGB, tomo LXX, parte II, 1908.

DOSSIÊ DO MARACATU NAÇÃO: Inventário Nacional De Referências Culturais - INRC do Maracatu Nação. Disponível<http://portal.iphan.gov.br/uploads/ckfinder/arquivos/DOSSIE_MARACATU_NA\%C3\%87\%C3\%830. pdf >.Acesso em: 12 janeiro 2017.

FREIRE, Paulo. Conscientização e Alfabetização: uma nova visão do processo. Revista de Cultura da Universidade do Recife. № 4; abril-junho, 1963.

FREIRE, Paulo. Ação cultural para a liberdade. $5^{\text {a }}$ ed., Rio de Janeiro, Paz e Terra.1981. FREIRE, Paulo. Extensão ou comunicação? ,6. ed. Rio de Janeiro: Paz e Terra, 1982.

FREIRE, Paulo. Ernani Maria Fiori, Prefácio a Paulo Freire, Pedagogia do Oprimido. Rio de Janeiro: Paz e Terra,1987.

GEERTZ, Clifford. A interpretação das culturas. Rio de Janeiro: Guanabara Koogan, 1989.

GOMES, Nilma Lino. Alguns termos e conceitos presentes no debate sobre relações raciais no Brasil: uma breve discussão. In: Educação antirracista: caminhos abertos pela Lei Federal no 10.639/03. Brasília: MEC/SECAD, 2005. 
GOMES, Nilma Lino. Educação, relações étnico-raciais e a Lei 10.639/03: breves considerações. In: BRANDÃo, Ana Paula (org.) Modos de fazer: caderno de atividades, saberes e fazeres. Rio de Janeiro: Fundação Roberto Marinho, 2010.

GUERRA-PEIXE, César. Maracatus no Recife. São Paulo: Ricordi, 1955.

GUIMARÃES, A. S. A. Racismo e antirracismo no Brasil. São Paulo: 34, 1999.

HALL, Stuart. Da diáspora: Identidades e mediações culturais. Belo Horizonte,2011.

MUNANGA, Kabengele. Org. Estratégias e Políticas de combate à discriminação racial. Editora da Universidade de São Paulo: Estação Ciência, 1996.

NAÇÃo, do Maracatu Porto Rico. Disponível em: https://nacaoportorico.maracatu.org.br/. Acesso em 10 out. 2019.

RAMOS, Lázaro. Na minha pele. Rio de Janeiro: Schwarcz, 2017.

REAL. Katarina. Eudes: o Rei do Maracatu. Recife: Fundação Joaquim Nabuco, Editora Massangana, 2001.

SANTOME, Jurjo Torres. Alienígenas na sala de aula. Introdução aos estudos culturais em educação. Tomaz Tadeu da Silva (org.). Petrópolis, RJ: Vozes, 1995.

SILVA, Ana Cláudia Rodrigues da. VAMOS MARACATUCÁ!!! Um estudo sobre os maracatus cearenses. Dissertação submetida à Coordenação do Programa de Pós-Graduação em Antropologia do Centro de Filosofia e Ciências Humanas da Universidade Federal de Pernambuco. Departamento de Ciências Sociais, Universidade Federal do Ceará, Fortaleza, 2004.

SOARES, Mariza. A 'nação' que se tem e a 'terra' de onde se vem: categorias de inserção social de africanos no Império português, século XVIII. Estudos Afro-Asiáticos, v. 2, n. 26,2004.

SOUSA, Francisca Maria do Nascimento. Linguagens escolares: reprodução do preconceito. In: Educação antirracista: caminhos abertos pela Lei Federal no10.639/03. Secretaria de Educação Continuada, Alfabetização diversidade - Brasília: MEC, SEC, Alfabetização e Diversidade, 2005b. Coleção Ed. Para Todos.

\section{(cc) EY}

Este trabalho está licenciado com uma Licença Creative Commons - Atribuição 4.0 Internacional. 